\title{
Joining and Socialization in Open Source Women's Groups: An Exploratory Study of KDE-Women
}

\author{
Yixin Qiu, Katherine J. Stewart, and Kathryn M. Bartol \\ University of Maryland, Van Munching Hall, College Park, MD 20742, USA \\ \{yqiu, kstewart, kbartol\} @rhsmith. umd. edu
}

\begin{abstract}
This research investigates how women's groups facilitate people's participation in the open source community by examining the joining activities in $K D E$ Women. Leveraging literatures on group membership roles and socialization, and adopting a qualitative research method, a joining script of different kinds of participants was identified. It is found that members developed organizational and leadership skills and were engaged in defining group norms and values upon joining KDE Women. This study extends prior literature on socialization and provides better understanding of women's groups in open source.
\end{abstract}

Keywords: women's group, membership roles, joining, socialization, qualitative.

\section{Introduction}

Open source software (OSS) projects are increasingly recognized as an important domain of technological innovation. They constitute an important means of involvement in technical work and in informal networks that aid the acquisition and maintenance of technical expertise. Several studies have highlighted the importance of attracting and retaining participants needed for the success of OSS projects $[10,16$, 25,27]. Consistent with the general finding that women's rates of participation in IT related fields remain relatively low across both the United States and Europe [4,23,29], survey and anecdotal evidence have indicated that attracting and retaining women participants in OSS projects has been particularly challenging [13,28].

Recognizing the under-representation of women in OSS, several "grass roots" women's groups have formed to focus on facilitating the involvement of women in OSS. These are volunteer-led online groups that aim to provide a forum and resources for women participants in OSS projects, and ultimately seek to increase the number of female participants contributing to OSS. Examples of these groups include LinuxChix, KDE Women, Ubuntu Women, and Debian Women.

Prior research has focused on identifying barriers to women's participation in technical work (e.g., work-life conflict), and on understanding the impacts of diversity in work settings [1,4,5]. The FLOSSPOLS 2006 [24] presents some rather alarming findings about the gender issue in the open source community. They suggest that women are treated as either alien other or (in online contexts) are assumed to be male and thus made invisible. Women's contributions in areas other than coding receive less 
valuation. Inflammatory talk and aggressive posturing exacerbates the confidence difficulties women tend to have [p.5].

Little research however, has explored the processes by which women actually do become involved in technical work, and, in particular, the role online grass roots women's groups may play in such involvement. An understanding of this is of critical importance for attracting women into the open source field because design guidelines could be drawn to make these online groups more effective in achieving their goals. Furthermore, people's interaction patterns found in these online women's open source groups will shed light on similar grass roots efforts in the offline settings and in other technology domains where lack of women's participation is an issue. This research intends to address the research gap by analyzing the actual group joining and socialization practices of one OSS women's group: KDE Women. KDE is a widely used desktop environment for UNIX workstations. KDE Women is a KDE sub-project, along with KDE-devel, KDE-Accessibility, KDE-Artists, KDE-edu, KDE-Usability, etc. The main goal of KDE Women is to "build an international KDE forum for women by providing a place where women can present what they already contribute to KDE and where women, who want to contribute, find a starting point." Through this project, they "actively want to contribute to the success of KDE" (http://women.kde.org/aboutus/ announcement.php, accessed March, 2008).

According to Tilly [26], "joining" is a behavioral script that provides a structure for the activity of becoming a member of a collective action project. Prior research on joining patterns in OSS has identified patterns based on the amount and type of early activities of a member and demonstrated that certain kinds of joining scripts were associated with the later technical contribution of members [27]. Building on this definition, the study addresses two research questions. First, what joining and initial socialization activities are associated with participation in KDE Women? Second, do joining and socialization differ for people in different KDE participation phases and if so, how? Given the relatively limited prior works on female participation in open source and the exploratory nature of the study, we adopted a qualitative research method by combining the deductive and inductive coding method to answer these two research questions $[11,17]$.

Von Krogh et al. [27] proposed that participants behaving according to a particular kind of joining script were more likely to be granted access to the developer community than participants who do not follow the joining script. Following on this work, we expect that identifying the joining scripts in OSS women's groups will be important to provide a window for further understanding the processes and practices through which a women's group facilitates women's participation in open source. Given the relatively broad mission of OSS women's groups, we take a broad view of participation, including both technical and non-technical activities (e.g., project documentation and general leadership activities).

We differentiate KDE Women participants into three categories based on their participation phases: those who have participated in other KDE groups before KDE Women, those who limit their participation to KDE Women only, and those who later engage in other KDE subgroups after KDE Women. Knowledge of people's joining patterns based on different participation phases will render a more nuanced understanding of the role of OSS women's 
groups. Potentially more targeted implications with respect to people's different motivations in joining OSS women's groups can be drawn from this investigation.

\section{Theoretical Background}

In order to understand the initial group joining behavior, we leverage literatures on group roles and group socialization of newcomers and combine this with an inductive analysis of the content unique to the group studied. In one of the seminal works on group membership roles, Benne and Sheats [6] identified three categories of functional member roles. 1) Group task roles. Members assuming these roles facilitate and coordinate group effort in the selection and definition of a common problem and in the solution of that problem [p.42]. Examples include initiator-contributor, information giver, information seeker, opinion giver, opinion seeker, coordinator, etc. 2) Group building and maintenance roles. Contributions of these roles are to alter or maintain the group way of working, to strengthen, regulate and perpetuate the group as a group [p.42] Examples include encourager, harmonizer, compromiser, etc. 3) Individual roles. The outcome of these roles is some individual goal which is not relevant either to the group task or to the functioning of the group as a group [p.43]. Examples in this category include aggressor, blocker, recognition-seeker, etc. While most research suggests that these group membership roles function in the offline face to face setting [15], Maloney-Krichmar \& Preece [21] demonstrates that the group membership role schema by Benne and Sheats applies to members in the online setting as well. Through a study of an online health community, they found that such analysis can serve as a useful diagnostic tool in the online environment for determining if there are differences in the stated purpose of a group and the roles that members play [p.16].

Literatures on individuals' adaptation behavior in organization $[2,12,14]$ identify different types of information people seek. Morrison [22] maintains that information seeking can facilitate newcomers' socialization process in terms of their task mastery, role clarification, acculturation, and social integration. The prior work shows that newcomers seek five types of information: (1) technical information, which is information about how to perform job tasks; (2) performance feedback, which is information about the appropriateness or correctness of fulfilling tasks; (3) referent information, which is information about job requirements and expected role behaviors; or what is expected of you in your job, (4) normative information, which is information about an organization's norms and values; or behaviors and attitudes that the firm values and expects, and (5) social feedback, which is information about how one's social behavior is being perceived and evaluated by others [p.174].

Based on these literatures we focus our qualitative investigation on understanding the initial roles that members play (task, group building or maintenance, or individual) and what information is sought or provided during members' initial interactions. Prior work on newcomer socialization has not examined the seeking and giving behaviors in a same context. Therefore, using the five types of seeking content and the membership role schema as a basis, we extended the coding to assess the "giving" and other actions associated with the different content of the socialization activities, in addition to the "seeking" action. 
The next section discusses our methodological approach including the data collection approach and the analytical processes employed. This is followed by preliminary results from our analysis. We then discuss the implications from our findings.

\section{Methodology}

\subsection{Data Collection}

As mentioned earlier, multiple grass roots women's groups were identified. We selected KDE Women over others as a case to study women's joining and socialization in the open source world, because a relatively complete history of the group is available. As of May 2007, the group's activities tapered off: on average one message was added in each subsequent month. In spite of that, the group had been well established since its founding in 1998, and reached critical mass during the period from February 2001 to May 2005. A complete history of a well-developed group has advantages over other ongoing groups for capturing various joining and socialization patterns of people with different participation levels.

Because many of the activities and interactions within both KDE Women and the KDE OSS projects are conducted online through email lists, we looked into the archives of these lists as our main data source. We identified the email addresses of every person who has ever posted a message to the KDE Women mailing list and developed tools to download all messages in all threads in which these people have posted a message, both on the KDE Women's list and other email lists associated with the KDE projects. There are 89 people who have posted on KDE Women at least once. Table 1 shows descriptive statistics about people's participation length in KDE Women ("Days

Table 1. Descriptive statistics of participation in KDE Women (KDEW) and KDE-affiliated projects (KDE)

\begin{tabular}{lllll}
\hline & $\begin{array}{l}\text { Days in } \\
\text { KDEW }\end{array}$ & $\begin{array}{l}\text { Days in } \\
\text { KDE }\end{array}$ & $\begin{array}{l}\text { Number of } \\
\text { messages in } \\
\text { KDEW }\end{array}$ & $\begin{array}{l}\text { Number of } \\
\text { messages in } \\
\text { KDE }\end{array}$ \\
\hline \multicolumn{5}{c}{ KDE then KDEW (N=28) } \\
\hline Average & 620.07 & 1868.11 & 8.96 & 760.96 \\
Max & 2125 & 3701 & 105 & 3912 \\
Min & 1 & 1 & 1 & 1 \\
\hline \multicolumn{5}{c}{ KDEW only (N=51) } \\
\hline Average & 90.45 & n/a & 2.14 & $\mathrm{n} / \mathrm{a}$ \\
Max & 2196 & n/a & 14 & n/a \\
Min & 1 & n/a & 1 & n/a \\
\hline \multicolumn{5}{c}{ KDEW then KDE (N=10) } \\
\hline Average & 184.5 & 297.4 & 2.9 \\
Max & 1277 & 1381 & 11 & 5.9 \\
Min & 1 & 1 & 1 & 18 \\
\hline
\end{tabular}


in KDEW") and other KDE-affiliated projects ("Days in KDE") as well as their posting activities, all of which were documented since people's first post in either KDE Women or other KDE projects to the date of data collection in July 2007. Based on the dates of these 89 people's first posts, we identified people at three participation phases.

\subsection{Data Analysis}

As mentioned earlier, a combination of deductive and inductive qualitative coding method was used to address the research questions. Every person's message(s) in their first thread posted on the mailing list of KDE Women were coded to capture the joining patterns. For the deductive coding of the joining activities, we utilized the group membership roles by Benne \& Sheats [6] and the five types of information seeking behaviors for newcomers' socialization [22] as a coding scheme. In the meantime, we allow new meanings to emerge from the data, resulting in new categories.

Data were coded using NVivo 7.0. For the deductive coding, two researchers first independently coded the same subset of the data according to the coding scheme and then compared the results. After consensus was reached, each researcher coded half of the rest of the data. For the inductive coding, each researcher first developed new categories for a same cluster of data. These categories were compared and the interpretations of differences in the coding were reconciled. This process continued for another round and a condensed list of categories were finalized when a high level of agreement across researchers was reached and most messages were adequately coded using the existing set of categories.

\section{Findings}

\subsection{Joining and Initial Socialization Activities on $K D E$ Women}

In this research, we are interested in exploring the joining behaviors of KDE Women participants. Adopting a qualitative approach, we developed a joining script of these people through combining the literatures on group membership roles, newcomer socialization, and inductive coding technique.

The first research question is on finding out the joining and initial socialization activities associated with participation in KDE Women. We found that the key group membership roles exhibited in the KDE Women are five types: information seeker, opinion seeker, information giver, opinion giver, and encourager. Except for "encourager", which is a group building and maintenance role, the others are task roles [6].

Socialization literatures indicate that newcomers usually seek five kinds of information: technical information, performance feedback, referent information, normative information, and social feedback. Building on this framework, our findings bring forth finer-grained dimensions and new meanings of these socialization activities in $K D E$ Women. For KDE Women members, the technical component relates to using or developing specific software programs. The performance component includes group-related tasks, such as building, promoting or representing KDE Women in the KDE community in general. The referent dimension is concerned with members' 
seeking of job requirements and identity in KDE Women. The normative dimension elaborates on issues such as group goal setting, group legitimacy and composition, and technological ideology debate. Specifically, early KDE Women members collectively determined the group goal and mission statement (group goal setting). After the group was formed, later joined participants had heated debate on whether the KDE Women group was being sexist, and whether men should be allowed in the group (group legitimacy and composition). During the group discussions, the war between open source and windows was constantly brought up (technology ideology debate). And lastly, the social dimension was mainly concerned with people's communication behaviors where they expected others' response.

Linking these socialization activities with the membership roles creates a complete configuration of the joining script in KDE Women, as shown in Table 2. Cells with a number suggest the frequency of a particular type of joining script where members take on certain roles in specific socialization activities, therefore indicating the kind of behavioral structures people engage in when becoming a member of KDE Women. Grayed areas indicate no such behavioral structures were found. For example, the combination of "information seeker" and "technical" creates one kind of joining script, meaning that participants in KDE Women would seek technical related information. However, no joining script exists as a combination of "opinion seeker" and "technical", showing that no one seems to seek technical opinions while first joining the group. As shown in Table 2, there are several kinds of joining script. Firstly, people seek and give

Table 2. Joining script of KDE Women members

\begin{tabular}{|c|c|c|c|c|c|}
\hline \multirow[b]{2}{*}{$\begin{array}{c}\text { Socialization } \\
\text { Activities }\end{array}$} & \multicolumn{5}{|c|}{ Major group membership roles played } \\
\hline & $\begin{array}{l}\text { Information } \\
\text { Seeker }\end{array}$ & $\begin{array}{l}\text { Opinion } \\
\text { Seeker }\end{array}$ & $\begin{array}{l}\text { Information } \\
\text { Giver }\end{array}$ & $\begin{array}{l}\text { Opinion } \\
\text { Giver }\end{array}$ & Encourager \\
\hline 1. Technical & 16 & & 5 & 1 & \\
\hline $\begin{array}{l}\text { 2. Performance } \\
2.1 \text { Group tasks }\end{array}$ & 7 & 6 & 1 & 3 & 2 \\
\hline 3. Referent & 9 & & & & 1 \\
\hline $\begin{array}{l}\text { 4. Normative } \\
\text { 4.1 Group goal }\end{array}$ & & & 2 & 3 & 8 \\
\hline $\begin{array}{l}4.2 \text { Group le- } \\
\text { gitimacy and } \\
\text { composition }\end{array}$ & & & 2 & 10 & 2 \\
\hline $\begin{array}{l}4.3 \text { Technologi- } \\
\text { cal ideology }\end{array}$ & & & 3 & 3 & \\
\hline $\begin{array}{l}\text { 5. Social } \\
\text { 5.1 Communica- } \\
\text { tion stimulation }\end{array}$ & 11 & & 2 & & 1 \\
\hline
\end{tabular}

Note. Numbers indicate frequency of KDE Women members' joining script of that configuration. Grayed area: no joining script found. 
information, as well as give opinions on technical issues. Secondly, they seek and give information, as well as seek and give opinions, and encourage each other on group tasks-related issues. Thirdly, for job requirement and membership identity issues, $K D E$ Women members only seek for feedback and being encouraging about that, but don't engage in any giving activities. Fourthly, KDE Women members give information and opinions and provide encouragement on normative issues; and yet they don't seek anything on this dimension. Lastly, they seek social feedback and provide information or encouragement to be social, especially when they want to stimulate some conversations on the mailing list.

\subsection{Joining Activities across People at Different Participation Phases}

The second research question addresses whether joining activities differ for people in different KDE participation phases and if so, how? In Table 3, which is adapted from Table 2, "A" stands for people who participated in KDE Women after KDE $(\mathrm{N}=28)$, "B" stands for those who participated in $K D E$ Women only $(\mathrm{N}=51)$, and "C" stands for those who participated in KDE after KDE Women $(\mathrm{N}=10)$. It shows where participants of $K D E$ Women stand respectively in the joining script configuration. In other words, it demonstrates which of the three groups belong to which joining script configuration. For example, all three types of people seek technical information, type A and type B people seek opinions on group tasks, and only type B people give opinions on technical

Table 3. Joining script of KDE Women members at three different phases

\begin{tabular}{|c|c|c|c|c|c|}
\hline \multirow[b]{2}{*}{$\begin{array}{c}\text { Socialization } \\
\text { Activities } \\
\end{array}$} & \multicolumn{5}{|c|}{ Major group membership roles played } \\
\hline & $\begin{array}{c}\text { Information } \\
\text { Seeker }\end{array}$ & $\begin{array}{l}\text { Opinion } \\
\text { Seeker }\end{array}$ & $\begin{array}{c}\text { Information } \\
\text { Giver }\end{array}$ & $\begin{array}{c}\text { Opinion } \\
\text { Giver }\end{array}$ & Encourager \\
\hline 1. Technical & $\mathrm{ABC}$ & & $\mathrm{AB}$ & $\mathrm{B}$ & \\
\hline $\begin{array}{l}\text { 2. Performance } \\
2.1 \text { Group tasks }\end{array}$ & $\mathrm{AB}$ & $\mathrm{AB}$ & A & A & $\mathrm{AB}$ \\
\hline 3. Referent & B & & & & B \\
\hline $\begin{array}{l}\text { 4. Normative } \\
\text { 4.1 Group goal }\end{array}$ & & & A & $\mathrm{AC}$ & $\mathrm{AB}$ \\
\hline $\begin{array}{l}4.2 \text { Group le- } \\
\text { gitimacy and } \\
\text { composition }\end{array}$ & & & $\mathrm{AC}$ & $\mathrm{ABC}$ & $\mathrm{AB}$ \\
\hline $\begin{array}{l}4.3 \text { Technological } \\
\text { ideology }\end{array}$ & & & B & $\mathrm{AB}$ & \\
\hline $\begin{array}{l}\text { 5. Social } \\
5.1 \text { Communica- } \\
\text { tion stimulation }\end{array}$ & $\mathrm{ABC}$ & & $\mathrm{AB}$ & & B \\
\hline
\end{tabular}

Note. "A": people who participated in KDE Women after KDE (N=28); "B": people who participated in $K D E$ Women only $(\mathrm{N}=51)$, "C": people who participated in KDE after $K D E$ Women $(\mathrm{N}=10)$. Grayed area: no joining script found. 
information. Below characteristics of these people's joining scripts on KDE Women will be presented. They are illustrated by sample quotes, and the corresponding codes representing joining scripts are included in the parentheses. These quotes are not meant to be exhaustive; rather, they are most representative of the joining activities of people at the three participation phases.

\subsubsection{People Who Participated in KDE Women after KDE (Denoted as A in Table 3)}

There are 28 people in this category. As demonstrated in Table 3, this group of people was very involved in group tasks issues and normative issues. They assumed all roles related to the former and all but information giver on the technological ideology issue to the latter. For example, this person was looking for volunteers to help with the $K D E$ Women booth at the Linux Expo:

"Hello all, I am just in the process of organising the KDE booth at the Linux Expo's in London (3/4 July) and Birmingham (12/13 Sep)...I am looking for some kde-women representation at the booth. If you can help with the following, please get in touch..." (Performance / group task information seeker)

Another person gave suggestions as to what a PR article should cover about $K D E$ Women:

"I think it's important to mention in the article that it's not only for women to participate. Rather it seems from the website that the focus is to get more women invovled with KDE and to address gender-specific issues in KDE." (Performance / group tasks - opinion giver)

This person presented ideas on involving more women in KDE:

"What we want to do about this: getting women involved into KDE as an integrated part. Let them give the audience and the chance to change computing in a way they think it is right for them also....That also makes $K D E$ the only project until now I know of that cares about women's needs generally in connection with the design and usage of graphical computer interfaces." (Normative / group goal - information giver)

People in this category were also interested in technical issues: they were both information seeker and information giver on software usage or development. An example is as follows:

"I'm in desperate need of a program that:

- has an interface to KOrganizer to keep track of dates

- has an interface to MySQL to maintain a musicians and customers database

- can do bookkeeping WITH the option of taking the VAT out by triple booking",

(Technical - information seeker) 
In addition to the above joining activities, this group extended communication on the list in hope of receiving feedback from others by performing the information seeker and information giver roles. Interestingly, this group was not engaged in referent issues, probably because they were very clear about their membership identity, so it would be unnecessary for them to seek information on their responsibility for the group.

\subsubsection{People Who Only Participated in KDE Women and Not Other KDE Projects (Denoted as B in Table 3)}

In total 51 people belong to this category. Being the largest group on KDE Women, these people were very social, in the sense that they gave encouragement to other group members' ideas and opinions in several aspects, and wanted to receive feedback on their greetings to the list. For example, in terms of normative issues, while they didn't comment on group goals, they showed encouragement on that:

"Second, I great appreciation for this list and its members. It is so nice to know other women who are thrilled with similar interests. I've never been a room with another female programmer... Look forward to the list." (Normative / group goal -- encourager)

This member ended the self-introduction with the hope to know more people on the group:

"I'm surprised at how much I have to say. I hope to get to know some of you-and learn from you." (Social / communication stimulation information seeker)

More interestingly, they were the only group that sought information regarding group membership identity. In other words, this group showed strong willingness to find a fit to contribute to the group:

"I'm not entirely sure how I can help, but I have a lot of skills and can probably help more than I know. I'm decently proficient in C... I mostly just like to help out." (Referent - information seeker)

In addition to the above examples, this group of people showed interest in technical issues, and they were both seekers and givers in this regard. The following quote illustrates that a person encountering a technical difficulty was seeking help:

"I've seen articles saying that it can be done but I'm having trouble actually doing it. I need to compile a*.so file for Solaris using a linux box...Has anybody done this?” (Technical - information seeker)

This person expressed interest in working out some technical issues:

"I'm fairly familiar with php, and I wouldn't mind working with other kde-women to set something like this up" (Technical - information giver) 


\subsubsection{People Who Participated in Other KDE Projects after KDE Women (Denoted as $\mathrm{C}$ in Table 3)}

The smallest group in KDE Women, this category has 10 people. Their main joining scripts centered on normative issues. They were information giver and opinion giver on group legitimacy and composition, as well as opinion giver on group goals.

"I'd like to see KDE women as a forum to encourage to write (well documented) code... not just lending a helping hand with documentation and stuff. Don't misunderstand me: documentation is important. But in my sparetime I'd rather write my own stupid KDE program (I hope one day I will...) that possibly will never reach the quality of say Konqueror instead of writing documentation for a boy who liked coding but disliked documentation." (Normative / group goal - opinion giver)

"As you can guess by the title I am against the group... Why bother, tell me something, are women Vess capable then everybody else... Is there some kind of issue with women $\backslash$ not being able to handle it on there own" (Normative / group legitimacy - opinion giver)

In the meanwhile, they sought information on technical issues, as illustrated by the following example:

"I'm trying to install KDE3 next to KDE2 following the instructions on the page "How to get KDE2 and KDE3 (from cvs) working on the same machine". ... which 4 lines are meant here? All help welcome best regards" (Technical - information seeker)

This group also sought social feedback from the list. While they were engaged in several seeking activities, they didn't seem to give back on those dimensions. Moreover, participants in this category did not show much concern about group related tasks, nor about their membership identity. They were also not engaged in much of the encourager role for any aspect of the joining activities.

\section{Discussions}

A comparison across these three categories of people indicates that there are two commonalities among them in terms of their joining and socialization activities. First, all three classes of members played the information seeker role on both technical and social dimensions. This suggests that people joined KDE Women in order to obtain answers to technical questions and receive feedback. A second similarity, which contrasts with prior literature, is that no one was engaged in the "seeking" activities regarding group normative information. Literatures on newcomers suggest the importance of adaptation to team expectations $[7,8,9,20]$, and the impact of information seeking about organization's norms and values on individuals' social integration in the organization [22]. What we found instead, is that rather than seeking information on the group norms, members participated in shaping the group norms and values - they were information and opinion givers and encouragers in this respect. This finding well 
reflects the dynamics on the gender issues in the open source world. While the implicit consensus is that open source is a male-dominated environment, a group dedicated to involving more women still stirred a great deal of debate and encountered many opposing view points. While many participants embraced the idea of a women's group, others objected, arguing, for example, that it served to segregate women rather than engage them. The norms and values of KDE Women thus remained in flux throughout the life of the group, and served as a common point of interest to bring engage all different kinds of members in discussion.

People at the three participation phases also reveal apparent differences in their joining and socialization patterns. For the group performance or tasks related activities, only people who had experience with KDE before entering the KDE Women's group were engaged in all aspects of the roles in this dimension. Through KDE Women, they were able to exercise organizational and leadership skills that, perhaps, they could not find the opportunity to develop in other KDE projects. People who never had any interactions with other KDE projects had diverse experience in KDE Women. Interestingly enough, only this group sought information regarding job requirements and membership identity, and showed encouragement to others on this dimension. Therefore, unlike those who were more experienced with KDE and took on group related tasks right away, these people, while very willing to contribute to KDE Women, were not quite sure how. Lastly, people who proceeded to other KDE projects from $K D E$ Women started their participation on KDE Women through discussion on the normative topics of the group. Unlike the other two groups however, upon joining, they were not involved in any group task related activities. They were also less social: they did not give or share much information with others, nor did they show an encouraging attitude to other people. Overall, this group seems to have engaged in the one topic most unique to $K D E$ Women: discussing the group itself, and targeted their task related participation to other KDE groups.

\section{Conclusion and Future Research}

In this research, we studied how women's groups facilitate people's participation in open source by investigating joining activities on KDE Women. Leveraging literatures on group roles and socialization, we developed an understanding of the joining scripts of different kinds of participants and thereby identified activities that people engage in to become a member of the group. In particular, we found two unique ways that $K D E$ Women appeared to provide a place for participants to engage in ways that may not have been available to them in the broader KDE environment. These were (1) by providing an opportunity for members to develop their leadership skills and (2) by providing a place for members to participate in the development of an environment with norms and values consistent with their own vision. This study extends prior literature on socialization by including the giving side of members' activities on different dimensions. We also illustrated joining patterns of members at three participation phases, and thus highlighted the different ways in which people utilized women's group for their participation in open source. 
The study remains a work in progress. As we continue with the research, we plan to expand our data coding and analysis in several ways. In particular, we plan to examine later threads of KDE Women members to understand their subsequent activities, and the outcomes of the various joining activities. We also plan to extend the study to other women's groups to gain a more comprehensive understanding of how these groups facilitate the participation of women and which of their practices are most successful and most likely to be adaptable to other contexts, such as the incorporation of women into professional technical roles.

Acknowledgements. We would like to thank Chang-han Jong and Lydia Chiu for excellent research assistance.

\section{References}

1. Ahuja, M.K.: Women in the Information Technology Profession: A Literature Review, Synthesis and Research Agenda. European Journal of Information Systems 11(1), 20-34 (2002)

2. Ashford, S.J.: The Role of Feedback Seeking in Individual Adaptation: A Resource Perspective. Academy of Management Journal 29(3), 465-487 (1986)

3. Ashford, S.J., Taylor, M.S.: Adaptation to Work Transitions: An Integrative Approach. In: Ferris, G.R., Rowland, K.M. (eds.) Research in Personnel and Human Resource Management, pp. 1-39. JAI Press, Greenwich (1990)

4. Bartol, K.M., Aspray, W.: The Transition of Women from the Academic World to the IT Workplace: A Review of the Relevant Research. In: Cohoon, J.M., Aspray, W. (eds.) Women in Information Technology: Research on Underrepresentation, pp. 377-419. MIT Press, Cambridge (2006)

5. Bartol, K.M., Williamson, I.O., Langa, G.A.: Gender and Professional Commitment among IT Professionals: The Special Case of Female Newcomers to Organizations. In: Cohoon, J.M., Aspray, W. (eds.) Women in Information Technology: Research on Underrepresentation, pp. 421-438. MIT Press, Cambridge (2006)

6. Benne, K.D., Sheats, P.: Functional Roles of Group Members. Journal of Social Issues 4(2), 41-19 (1948)

7. Chatman, J.A.: Matching People and Organizations: Selection and Socialization in Public Accounting Firms. Administrative Science Quarterly 36(3), 459-484 (1991)

8. Chen, G., Klimoski, R.: The Impact of Expectations on Newcomers on Newcomer Performance in Teams as Mediated by Work Characteristics, Social exchanges, and Empowerment. Academy of Management Journal 46(5), 591-607 (2003)

9. Chen, G.: Newcomer Adaptation in Teams: Multilevel Antecedents and Outcomes. Academy of Management Journal 48(1), 101-116 (2005)

10. Crowston, K., Annabi, H., Howison, J.: Defining Open Source Software Project Success. Paper presented at the International Conference on Information Systems, Seattle, WA (2003)

11. Duriau, V.J., Reger, R.K., Pfarrer, M.D.: The Content Analysis of Content Analysis. Organizational Research Methods 10(1), 5-34 (2007)

12. Feldman, D.C.: A Contingency Theory of Socialization. Administrative Science Quarterly 21(3), 433-452 (1976)

13. Ghosh, R.A., Glott, R., Krieger, B., Robles, G.: Free/Libre Open Source Software: Survey and Study. In: Workshop on Advancing the Research Agenda on Free/Open Source Software, International Institute of Infonomics, University of Maastricht, Brussels, Netherlands (2002) 
14. Graen, G.: Role Making Processes Within Complex Organizations. In: Dunnette, M.D. (ed.) Handbook of Industrial and Organizational Psychology, pp. 1201-1245. Rand McNally, Chicago (1976)

15. Hare, A.P.: Roles, Relationships, And Groups In Organizations: Some Conclusions And Recommendations. Small Group Research 34(2), 123-154 (2003)

16. Hars, A., Ou, S.: Working for Free? Motivations for Participating in Open Source Projects. International Journal of Electronic Commerce 6(3), 25-39 (2002)

17. Hennig-Thurau, T., Walsh, G.: Electronic Word-of-Mouth: Motives for and Consequences of Reading Customer Articulations on the Internet. International Journal of Electronic Commerce 8(2), 51-74 (2003)

18. Katz, R.: Time and Work: Toward an Integrative Perspective. In: Staw, B.M., Cummings, L.L. (eds.) Research in Organizational Behavior, pp. 81-127. JAI Press, Greenwich (1980)

19. Louis, M.R.: Surprise and Sense-making: What Newcomers Experience in Entering Unfamiliar Organizational Settings. Administrative Science Quarterly 25(2), 226-251 (1980)

20. Louis, M.R.: Newcomers as Lay Ethnographers: Acculturation During Socialization. In: Schneider, B. (ed.) Organizational Climates and Cultures, pp. 85-129. Jossey-Bass, San Francisco (1990)

21. Maloney-Krichmar, D., Preece., J.: A Multilevel Analysis of Sociability, Usability, and Community Dynamics in an Online Health Community. ACM Transactions on Computer-Human Interaction 12(2), 1-32 (2005)

22. Morrison, E.W.: Longitudinal Study of the Effects of Information Seeking on Newcomer Socialization. Journal of Applied Psychology 78(2), 173-183 (1993)

23. National Center for Educational Statistics, Table 46, http://www.nsf.gov/statistics/nsf $04311 /$ pdf/sectb.pdf (2004)

24. Nafus, D., Leach, J., Krieger, B.: Gender: Integrated Report of Findings. Free/Libre and Open Source Software: Policy Support FLOSSPOLS. Deliverable D 16, cover page (2006)

25. Roberts, J.A., Hann, I.-H., Slaughter, S.A.: Understanding the Motivations, Participation, and Performance of Open Source Software Developers: A Longitudinal Study of the Apache Projects. Management Science 52(7), 984-999 (2006)

26. Tilly, C.: Durable Inequality. University of California Press, Berkeley (1999)

27. Von Krogh, G., Spaeth, S., Lakhani, K.R.: Community, Joining, and Specialization in Open Source Software Innovation: a Case Study. Research Policy 32(7), 1217-1241 (2003)

28. Weiss, T.R.: Panel: Open-Source Needs More Women Developers. Computerworld (2005)

29. White House Council of Economic Advisors. Opportunities and Gender Pay Equity in New Economy Occupations. Available in the National Archives (2000)

30. Wu, C., Gerlach, J.H., Young, C.E.: An Empirical Analysis of Open Source Software Developers Motivations and Continuance Intentions. Information \& Management 44(3), 253-262 (2007) 